Res Publica. Revista de Historia de las Ideas Políticas

ISSN: $1576-4184$

\title{
Michel Foucault y la genealogía del sujeto moderno: gobierno, libertad, verdad de sí
}

\author{
Beatriz Dávilo*
}

Recibido: 16 de septiembre de 2016 / Aceptado: 11 de diciembre de 2017

Resumen. Este artículo intenta reconstruir la genealogía de la subjetividad moderna que propone Michel Foucault a lo largo de su producción, vinculando el ejercicio crítico en torno al sujeto como conciencia soberana desplegado en los años '60, con la reflexión sobre el sujeto de la gubernamentalidad liberal que aparece en Seguridad, territorio y población y Nacimiento de la biopolítica, y el análisis de la veridicción de sí desarrollado los últimos cursos dictados en el Collège de France. En este sentido es posible rastrear cierta continuidad en el abordaje de la problemática de la subjetividad moderna, en la medida en que el intento por desmontar la imagen de la soberanía del sujeto que hace Foucault en Las palabras y las cosas y la Arqueología del saber da cuenta del carácter de efecto de ese sujeto capaz de encontrar la verdad de sí, de su deseo y de su interés, que es central en la estrategia gubernamental del liberalismo. Ese sujeto se forja en la historia de Occidente a partir de una serie de tecnologías que van a habilitar una estructura subjetiva definida como interioridad, como pliegue sobre sí mismo, como autocontemplación del yo. El sujeto moderno así forjado, a la vez que abona la racionalidad gubernamental del liberalismo, está atravesado por un ethos crítico en el marco del cual puede problematizar lo que es, lo que hace y el mundo en que vive, lo que le permite pensar, actuar y ser de otro modo.

Palabras clave: Foucault; gubernamentalidad; subjetividad; verdad; Modernidad.

\section{[en] Michel Foucault and the Genealogy of Modern Subject: Government, Freedom and the Truth of the Self}

\begin{abstract}
This article intends to trace the genealogy of modern subjectivity offered by Michel Foucault along his work, linking the critic of the subject as sovereign conscience-developed during the ' 60 s- with the reflexion on the subject of the liberal governmentality carried on in Security, territory, population and The birth of biopolitics, and the analysis of the veridiction of the self undertaken in the last seminars delivered at the College de France. In this sense, it is possible to observe a certain continuity in the approach to the problem of modern subjectivity, as we can see in the attempt to dismantle the image of the subject's sovereignty done in The order of the things and Archaeology of knowledge showing the effectual condition of the subject as an individual capable of finding the truth of its self, its desire, its interest, a crucial question in the governmental strategy of liberalism. That type of subject is forged, along the Western history, through a series of technologies that will enable a subjective structure defined as inwardness, as the folding of the self, as self-contemplation. The modern subject thus forged, as far as he is at the core of the liberal governmental rationality, is at the same time modelled by the critical ethos that prompts him to problematize what he is, what he does and the world where he lives, allowing him to think, to act and to reconstitute himself differently.
\end{abstract}

Keywords: Foucault; governmentality; subjectivity; truth; Modernity.

\footnotetext{
* Universidad Nacional de Entre Ríos (Argentina)

beatrizdavilo@hotmail.com
} 
Sumario: 1. Introducción. 2. La crítica de la violencia de Walter Benjamin. 3. Arendt y el problema de las revoluciones modernas. 4. Una complementariedad posible entre Benjamin y Arendt. 5. Consideraciones finales sobre el poder, la violencia y la revolución.

Cómo citar: Dávilo, B. (2018). Michel Foucault y la genealogía del sujeto moderno: gobierno, libertad, verdad de sí, en Res publica 21.1, 91-108.

\section{Introducción}

Sobre el final de la segunda clase del curso Seguridad, territorio, población-dictado en el Collège de France en 1978-, Michel Foucault plantea que el liberalismo se liga a una técnica política que no se despega "del juego de la realidad consigo misma". Se trata de una tecnología en la que el gobierno de los hombres se sostiene fundamentalmente en la libertad de éstos, en lo que "quieren hacer, lo que están interesados en hacer, lo que piensan hacer"'. Ahora bien, la estrategia gubernamental del liberalismo, para poder valerse de lo que los hombres quieren y piensan hacer, requiere de un tipo de sujeto apto para ser gobernado con la libertad según la lógica de su interés y su deseo. La pregunta sería, entonces, cómo se forja ese sujeto de la gubernamentalidad liberal.

Esta pregunta provee una clave de lectura de la producción foucaultiana que apunta a identificar los distintos modos en que el filósofo francés problematizó la constitución de la subjetividad moderna, y en particular de aquellos rasgos que se articulan a la racionalidad gubernamental del liberalismo. En esta perspectiva, se puede pensar en una secuencia de reflexión en la que el ejercicio crítico en torno al sujeto como conciencia soberana -desplegado en los trabajos de los años '60-, se ensambla sin dificultad con el trabajo sobre el sujeto de la gubernamentalidad liberal que aparece en Seguridad, territorio y población y Nacimiento de la biopolítica (1979), y con el problema de la veridicción de sí desarrollado en los últimos cursos ofrecidos en el Collège de France.

En este sentido, el itinerario foucaultiano tiene su primer acercamiento a la genealogía de la subjetividad moderna en Historia de la locura en la época clásica (1961), Las palabras y las cosas (1966) y la Arqueología del saber (1969), donde explora el umbral en el que se inscribe la emergencia del sujeto como conciencia soberana, a partir del análisis de una razón, a la vez subjetivante, opuesta a la locura como sin-razón, y objetivante, a través de las reglas de formulación de discursos que definen un campo de saberes en torno al' hombre' como productor de vida, de bienes y de significados.

En la pregunta por "el hombre" y su conciencia, por esa invención reciente que se borrará "como en los límites del mar un rostro de arena", puede visualizarse, como propone Miguel Morey, el "encofrado retórico" que preside la obra de Foucault", abocada a mostrar los modos históricos, contingentes, de configuración de los conceptos, las imágenes, las figuras, que constituyeron el suelo sobre el que se asentó el pensamiento occidental. Esta primera problematización abre el camino para los desarrollos posteriores en los que Foucault reflexiona en torno a los mecanismos de

\footnotetext{
M. Foucault, Seguridad, territorio, población, Buenos Aires, Fondo de Cultura Económica, 2006, clase del 18 de enero de 1978, p. 70.

Ibidem, p. 71.

M. Foucault, Las palabras y las cosas. Una arqueología de las ciencias humanas, Buenos Aires, Siglo XXI, 2008 [1966], p. 378.

4 M. Morey, Escritos sobre Foucault, Madrid, Editorial Sextopiso, 2014, p. 306.
} 
constitución de un sujeto capaz de encontrar la verdad de sí, de su deseo y de su interés, forjado en la historia de Occidente mediante una serie de tecnologías que van a habilitar una estructura subjetiva definida como pliegue, como "autocontemplación psicológica del yo"s. Este sujeto soberano, que puede conocer y conocerse, es una pieza central en la estrategia gubernamental del liberalismo, pero al mismo tiempo puede funcionar como el punto de apoyo de una suerte de reversión táctica, operada en los últimos años de Foucault: las tecnologías de sujeción son, entonces, interpeladas en su posibilidad de habilitar un espacio de acción para un sujeto ético que trabaja sobre sí y busca modelar una estética de su existencia a partir de su capacidad de interrogarse por lo que es y de decir el presente ${ }^{6}$.

\section{Gobierno y libertad en el liberalismo}

La idea de un gobierno que tome en cuenta lo que los hombres quieren hacer desplaza el problema del poder del campo de la guerra al de la gubernamentalidad. Si en el curso de 1976, Defender la sociedad, el modelo de la guerra es la matriz de análisis de las relaciones de poder, en Seguridad, territorio, población y Nacimiento de la biopolítica la gubernamentalidad toma el relevo a la hora de pensar las 'tácticas generales' del ejercicio del poder.

En efecto, en Defender la sociedad Foucault aborda las perspectivas que asocian el poder a la capacidad de reprimir y lo conciben según el modelo de la ley, según la lógica de la soberanía. Este acercamiento, según el filósofo francés, es incapaz de dar cuenta de los mecanismos infinitesimales de ejercicio del poder y de los operadores materiales de la dominación que producen sujetos -en el doble sentido de individuo que se reconoce a sí mismo como unidad de reflexión y acción, y de quien está sometido o subordinado ${ }^{7}$. La propuesta foucaultiana, en cambio, recurre a la guerra como analizador de las relaciones de poder y "matriz de las técnicas de dominación", en la medida en que "puede considerarse como el punto de tensión máximo, la desnudez misma de las relaciones de fuerza".

En el curso de 1978, en cambio, inscribe sus investigaciones en un ámbito que designa como la 'historia de la gubernamentalidad' en Occidente. Dice Foucault:

Con esta palabra "gubernamentalidad" aludo a tres cosas. Entiendo el conjunto constituido por las instituciones, los procedimientos, análisis y reflexiones, los cálculos y las tácticas que permiten ejercer esa forma bien específica, aunque muy

\footnotetext{
M. Foucault, El yo minimalista y otras conversaciones, Buenos Aires, La marca, 2003, p. 79.

6 En los últimos años, el debate en torno a la obra foucaultiana se ha visto enriquecido con una vasta producción, imposible de abordar en los límites de este artículo. A modo de ejemplo, y en relación a cuestiones cercanas al tema aquí tratado, podemos citar: G. De Lagasnerie, La dernière leçon de Michel Foucault. Sur le néoliberalisme, la théorie et la politique, Paris, Fayard, 2012; B. Han, "The Analytic of Finitude and the History of Subjectivity", en G. Gutting (ed.) The Cambridge Companion to Foucault, New York, Cambridge University Press, 2005, pp. 176-209; M.G.E. Kelly, The political philosophy of Michel Foucault, New York, Routledge, 2009; G. Le Blanc, El pensamiento Foucault, Buenos.Aires, Amorrortu, 2008; N. Nigro, "De la guerre à l'art de gouverner: un tournant théorique dans l'œuvre de Foucault ?", en Labyrinthe, $\mathrm{N}^{\circ}$ 22, 2005, pp. 15-25 ; J. Revel, Foucault, une pensé du discontinu, Paris, Mille et une nuit, 2010; D. Sardinha, "La découverte de la liberté", en Labyrinthe, $\mathrm{N}^{\circ} 22,2005$, pp. 89-99.

7 M. Foucault, Defender la sociedad, Buenos Aires, FCE, 2000, clases del 7 y el 14 de enero de 1976, pp. 29 y 42-47, respectivamente.

$8 \quad$ Ibidem, clase del 21 de enero, p. 52.
} 
compleja, de poder que tiene por blanco principal la población, por forma mayor de saber la economía política y por instrumento técnico esencial los dispositivos de seguridad. Segundo, por "gubernamentalidad" entiendo la tendencia, la línea de fuerza que, en todo Occidente, no dejó de conducir, y desde hace mucho tiempo, al tipo de poder que podemos llamar « gobierno» sobre todos los demás: soberanía, disciplina, y que indujo, por un lado, el desarrollo de toda una serie de aparatos específicos de gobierno, y [por otro] el desarrollo de toda una serie de saberes. Por último, creo que habría que entender la "gubernamentalidad" como el proceso o, mejor, el resultado del proceso en virtud del cual el Estado de justicia de la Edad Media convertido en Estado administrativo en los siglos XVI y XVII, se gubernamentalizó poco a poco 9 .

De estas tres dimensiones de la gubernamentalidad, la primera parece circunscribirse a la estrategia gubernamental de la Modernidad, cuyo núcleo es fundamentalmente biopolítico y su marco general es el liberalismo. Dice Foucault: "una vez que se sepa qué es ese régimen gubernamental denominado liberalismo, se podrá, me parece, captar qué es la biopolítica"10. Sin embargo, la segunda y la tercera amplían el arco temporal de la gubernamentalidad y permiten vislumbrar una genealogía que va mucho más atrás en el tiempo, definiendo las líneas de ese desplazamiento desde la guerra hacia el gobierno en los análisis foucaultianos.

Según Foucault, el análisis de las relaciones de poder, en su vinculación con el sujeto, debe situarse en un lugar que no sería "ni de violencia o de lucha, ni en uno de vínculos voluntarios, sino más bien en el área del modo singular, ni belicoso, ni jurídico, que es el gobierno" ¿"En qué consiste, entonces, ese modo particular de ejercicio del poder que es el gobierno, que no actúa según una lógica belicosa, pero tampoco jurídica? En la conducción de conductas. Esta idea se va perfilando con claridad desde Seguridad, territorio, población, donde habla de la centralidad que adquiere en la Modernidad el problema de quién se hace cargo de las conductas de los hombres, en un escenario donde la disputa por el gobierno admite varios interlocutores, entre los que podemos contar voces diversas que se sitúan en el discurso pedagógico, en el religioso y en el político; y se recorta con precisión en los últimos cursos, en los que articula el poder en tanto conjunto de "procedimientos por los cuales se gobierna la conducta de los hombres" con los modos de constitución de los sujetos mediante las prácticas de sí y las formas de veridicción ${ }^{12}$. En este marco, una de los mecanismos más sutiles del gobierno tiene que ver, como dice Foucault, con un trabajo que va del sí mismo al sí mismo $^{13}$, con esa forma de autorestricción en la cual es el individuo mismo el que se impone límites en la orientación de su propia conducta.

Si bien Foucault, hacia el final de su vida, está abocado a la indagación del problema del gobierno en la Antigüedad clásica y tardía y en el cristianismo, y por lo tanto no hace demasiadas referencias a la razón gubernamental de la Modernidad,

\footnotetext{
9 M. Foucault, Seguridad, territorio, población, op. cit., clase del 1 de febrero, p. 136.

10 M. Foucault, Nacimiento de la biopolítica, op. cit., clase del 10 de enero de 1978, p. 41. Hay un fragmento de los manuscritos que Foucault no lee en la clase, y que los editores incluyen a pie de página, donde aparece, casi como un programa de indagación "Estudiar el liberalismo como marco general de la biopolítica" (p. 40).

11 M. Foucault, "El sujeto y el poder”, en H. Dreyfus y P. Rabinow, Michel Foucault: más allá del estructuralismo y la hermenéutica, Buenos Aires, Nueva Visión, 2001, p. 254.

12 M. Foucault, El coraje de la verdad, Buenos Aires, FCE, 2010, clase del 1 de febrero de 1984, p. 27.

13 M. Foucault, Le gouvernement de soi et des autres, Paris, Gallimard, 2008, clase del 16 de febrero de 1983, p. 224.
} 
hay en ese recorrido, de cualquier manera, muchos elementos valiosos para analizar el vínculo entre gobierno y sujeto en el mundo moderno.

Entre esos elementos, el pastorado cristiano condensa las diferentes líneas de análisis en las que avanza la indagación foucaultiana: es una práctica de sí que liga al individuo a la verdad, da cuenta de las posibilidades de intervención en un debate que admite una multiplicidad de interlocutores -entre los cuales el sistema político es, durante mucho tiempo, sólo uno más entre tantos--, y configura una tecnología de individuación cuya mecánica podrá ser traslada al "gobierno político" cuando el Estado se gubernamentalice, como plantea Foucault.

El pastorado, en tanto técnica que se despliega sobre el individuo y el conjunto -la oveja y el rebaño- es una forma de atar a mujeres y hombres a la verdad, más aún cuando está articulado a la confesión. En realidad, el pastorado y la confesión están inscriptos en el régimen de verdad que establece el cristianismo,

un régimen definido por la obligación en que se ven los individuos de establecer consigo mismos una relación de conocimiento permanente, la obligación en que están de descubrir en el fondo de sí mismos secretos que se les escapan, la obligación en que están, por último, de manifestar esas verdades secretas a través de actos que tienen efectos específicos, mucho más allá de los efectos de conocimiento: efectos liberadores ${ }^{14}$.

A través de la figura del pastor, que se preocupa por el bienestar de sus ovejas, el gobierno funciona en el marco de un régimen de verdad que obliga al individuo a decir, y decirse, lo que es, lo que hace, lo que piensa, habilitando a las instituciones religiosas un amplio espacio de intervención en la conducción de conductas, en un escenario en el que el poder soberano todavía no controla las tareas "gubernamentales". De hecho, para Foucault, el gran problema político que se presenta en el siglo XVI tiene que ver con la posibilidad de articular gobierno y soberanía, y se manifiesta fundamentalmente en dos preguntas. La primera es: “¿en qué medida el ejercicio del poder soberano puede y debe lastrarse con cierta cantidad de tareas que hasta el momento no se le reconocían y que son justamente tareas de conducción" ${ }^{15}$. La segunda se interroga por el tipo de racionalidad, de cálculo, de pensamiento, según los cuales podrá gobernarse a los hombres en el marco de la soberanía ${ }^{16}$.

En relación a la primera pregunta, lo que vemos en la historia del Occidente Moderno es que la emergencia del Estado es coextensiva a esa preocupación por definir una racionalidad específica para el gobierno de los hombres en el marco de la soberanía. En este sentido, la razón de Estado, con sus dispositivos diplomáticomilitares y de policía, es la forma que encuentra la soberanía de articular el gobierno al ejercicio del poder. Es más, el poder de policía -con esa grilla que pretende atravesar ámbitos tan diversos como la higiene de la ciudad, las costumbres del pueblo, el abastecimiento de víveres y el disciplinamiento de la fuerza laboral- es tal vez la dimensión más específicamente gubernamental de la razón de Estado y da cuenta de los primeros intentos de adecuar a la lógica estatal la mecánica a la vez individualizadora y colectiva del pastorado.

\footnotetext{
M. Foucault, Del gobierno de los vivos, Buenos Aires, FCE, 2014, clase del 30 de enero de 1980, p. 107.

M. Foucault, Seguridad, territorio, población, op. cit., clase del 8 de marzo de 1978, p. 268.

Ibidem, p. 270.
} 
No obstante, el proceso que avanza hacia la gubernamentalización del Estado va a encontrar su punto de inflexión en la configuración de la racionalidad gubernamental del liberalismo, una racionalidad que se forja en la misma práctica de gobierno, según un principio de autolimitación: "la razón del menor gobierno como principio de organización del Estado" ${ }^{17}$. A diferencia de la policía - ese poder omniabarcador, que aspira a penetrar en todos los ámbitos de la vida individual y colectiva-, la tecnología gubernamental propia del liberalismo es la seguridad, que toma como punto de apoyo la realidad y actúa según un "dejar hacer" que aprehende las cosas en el nivel de su naturaleza y en el punto de su ocurrencia efectiva ${ }^{18}$.

Foucault dice que los dispositivos disciplinarios -que expresan una lógica de lo permitido y prohibido a partir de la cual se construye una grilla clasificatoriaoperan como un complemento de la realidad interviniendo antes de que eso que se reconoce como real o natural ocurra: reconocen que la conducta de hombres y mujeres es volátil y se resiste a las reglas, por eso ponen en marcha toda una serie de técnicas investidas en instituciones como la escuela, la fábrica, el ejército, que van a intentar que esa conducta no se produzca. En cambio los dispositivos de seguridad operan en el nivel de emergencia de lo real, jugando con sus efectos, y haciendo que se compensen, se moderen o se anulen: se acepta el carácter egoísta, adquisitivo y calculador de los individuos, y a partir de estos rasgos se definen las prácticas gubernamentales. De modo que el sujeto gobernable del liberalismo es el individuo con intereses, que orienta de manera previsible su conducta en función de éstos, y por lo tanto puede ser gobernado según un principio de frugalidad que apunta a intervenir lo menos posible.

En función de una estrategia gubernamental que pretende "gobernar con la libertad", el régimen liberal necesita producir y organizar esa libertad. Foucault dice que el liberalismo produce derechos porque los consume, los necesita para gobernar:

La libertad es algo que se fabrica a cada instante. El liberalismo no es lo que acepta la libertad, es lo que se propone fabricarla a cada momento, suscitarla y producirla con, desde luego, todo el conjunto de coacciones, problemas de costo que plantea esa fabricación ${ }^{19}$.

En este marco, la seguridad aparece como el principio de cálculo de ese costo de producción de la libertad. La seguridad en los análisis tradicionales de las teorías contractualistas y liberales es el plus que agrega el Estado al disfrute de los derechos. Según la matriz contractualista moderna, al ingresar a la sociedad los hombres ceden algunos derechos para poder conservar otros. La seguridad es lo que le agrega el Estado al disfrute de estos derechos. En Foucault ese elemento propio del Estado derecho se convierte en un parámetro de evaluación de los resultados políticos que emergen de la relación entre libertad individual e interés colectivo, y permite establecer la dinámica y los alcances de la tecnología securitaria.

Sin embargo, ese individuo con intereses, cuyo campo de acción está limitado en primer lugar por otros tantos individuos como él que conviven en la sociedad, no es, como dice Foucault, un átomo de libertad frente al gobierno. Al contrario, es

\footnotetext{
M. Foucault, Nacimiento de la biopolítica, op. cit., clase del 17 de enero de 1979, p. 44.

M. Foucault, Seguridad, territorio, población, op. cit., clase del 18 de enero de 1978, pp. 66-68.

M. Foucault, Nacimiento de la biopolitica, op. cit., clase del 24 de enero de 1979, p. 84.
} 
ya un sujeto apto para ser gobernado mediante la libertad. ¿Cuáles fueron entonces las condiciones de emergencia de esa matriz subjetiva que permite al liberalismo gobernar lo menos posible? Para responder a esta pregunta hay que volver la mirada hacia atrás y recorrer todas esas tecnologías que forjaron un sujeto que se piensa a sí mismo como una superficie de intervención de ese poder que va del sí mismo al sí mismo, como caracteriza Foucault a una de las formas más sutiles del gobierno. Este itinerario se inicia con la exploración de los modos en que se problematizó la relación entre el "hombre" y su "conciencia" en los albores de la Modernidad, para llegar a la reflexión en torno al "gobierno de los hombres por la manifestación de la verdad en la forma de la subjetividad"20.

\section{Genealogía del sujeto de la gubernamentalidad liberal}

El tramo del itinerario teórico y conceptual de Foucault que cubre buena parte de la década de 1960 está atravesado por una inquietud que, con modulaciones específicas, se mantendrá a lo largo de su obra: cómo se forja el sujeto como conciencia soberana, cuáles son los mecanismos que ubican al sujeto en un lugar exterior al discurso desde el cual dejaría en él "la traza inefable de su libertad". De lo que se trata es, en fin, de "poner en cuestión el tema de una subjetividad que constituiría las significaciones para transcribirlas después en el discurso"21.

En este recorrido, el tema de la locura puede considerarse una bisagra entre las primeras formas de problematización de la subjetividad y los posteriores análisis del vínculo entre gubernamentalidad y sujeto. Como señala Mathieu Potte-Bonneville, en las páginas que Foucault consagra a la Modernidad, el encuentro con la figura del 'loco' es fundamental para entender el empeño foucaultiano en

deshacer la universalidad mítica del hombre para afirmar al mismo tiempo su densidad histórica; en comprender la emergencia de un saber científico del individuo; en desmontar los mecanismos conjuntos del sujetamiento y de la mirada panóptica ${ }^{22}$.

En "La locura, ausencia de obra" -el apéndice de Historia de la locura en la época clásica en el que responde a Jacques Derrida- Foucault sitúa su análisis en las grietas que comienza a exhibir la figura del homo dialecticus,

el ser de la partida, del retorno y del tiempo, el animal que pierde su verdad y la encuentra iluminada, el extranjero a sí mismo que se vuelve familiar. Este hombre fue el sujeto soberano y el siervo objeto de todos los discursos sobre el hombre que se han pronunciado desde hace tiempo y, singularmente, sobre el hombre alienado. Y por fortuna, muere, durante esas habladurías ${ }^{23}$.

Este planteo que anuncia la muerte del "hombre" - desarrollada con más profundidad en Las palabras y las cosas- articula, por déficit, el problema de la locura

20 M. Foucault, Del gobierno de los vivos, op. cit., clase del 30 de enero de 1980, p. 103.

21 M. Foucault, "Respuesta a L'Esprit”, en El discurso del poder, Buenos Aires, Folios, 1985, p. 75.

22 M. Potte-Bonneville, Michel Foucault, la inquietud de la historia, Buenos Aires, Manantial, 2007, p. 68.

23 M. Foucault, Historia de la locura en la época clásica, México, FCE, 2003 [1961], cuarta reimpresión, tomo II, p. 330 . 
al de la conciencia y la interioridad: para la psiquiatría moderna, el loco se vuelve clasificable por lo que no puede captar en relación a su conciencia, en función de la distancia que lo separa de él mismo. El destino de la locura "se vinculó al del individuo humano entendido como interioridad singular y profunda”, como diría PotteBonneville $^{24}$. El discurso psiquiátrico requiere de una naturaleza subjetiva universal pensada como interioridad, que también subyace a la locura, siendo ésta la manifestación de desórdenes superficiales. Por eso las prácticas terapéuticas incitan al loco a explorar en su interior, empujan a la locura a mirarse a sí misma, sometiéndola, como diría Foucault, a la "humillación de ser para sí misma un objeto"25.

La posibilidad de que la locura se ofrezca como objeto de conocimiento y pueda ser gobernada a través de un acto de conciencia por el que el loco vuelve sus ojos sobre sí mismo es lo que la sitúa en el umbral de la enfermedad mental y habilita un conjunto de intervenciones médicas. Como dice Potte-Bonneville, "La interioridad del alienado es, desde el punto de vista mítico, el lugar donde la pretensión positiva de la psiquiatría puede echar raíces"26.

La locura instala el problema de la verdad del sujeto en una doble dimensión: como afirmación y como sospecha. Las posibilidades de intervención de la psiquiatría se ligan al reconocimiento, por parte del loco, de su propia locura; y en el momento en que se reconoce, la locura comienza, si no a desvanecerse, al menos a volverse gobernable. Y es aquí donde la psiquiatría encuentra su punto de apoyo, como ocurre en el caso reseñado por Foucault referido al paciente de François Leuret (1797-1851), que se cree Napoleón: la cura se inicia cuando el paciente acepta su propia biografía, vehiculizada a través del discurso imperativo del médico. Según Foucault, Leuret busca que el paciente

se aferre a su propia historia. Es necesario que el enfermo se reconozca en una especie de identidad constituida por una cantidad de episodios de su existencia. En otras palabras, el enfermo debe enunciar primeramente la verdad en ese reconocimiento de una serie de episodios biográficos: el enunciado más eficaz de la verdad no ser referirá a las cosas, sino al propio enfermo ${ }^{27}$.

Pero la verdad también irrumpe en el discurso psiquiátrico a través de su opuesto: la simulación. He aquí un problema mucho más complejo que el de la simple mentira del paciente, porque la "simulación interna de la locura" pone en el foco de la discusión el modo en que "un falso síntoma es una forma de estar verdaderamente enfermo" 28 .

A través de las figuras de la locura, Foucault vuelve una y otra vez sobre una cuestión clave para las ciencias humanas, según lo plantea en Las palabras y las cosas:

¿cómo hacer que el hombre piense lo que no piensa, habite aquello que se le escapa en el modo de una ocupación muda, anime, por una especie de movimiento

\footnotetext{
24 M. Potte-Bonneville, Michel Foucault, la inquietud de la historia, op. cit., p. 60.

25 M. Foucault, Historia de la locura en la época clásica, op cit., tomo II, p. 250.

26 M. Potte-Bonneville, Michel Foucault, la inquietud de la historia, op. cit., p. 61.

27 M. Foucault, El poder psiquiátrico, Buenos Aires, FCE, 2003, clase del 19 de diciembre de 1973, p. 189.

28 Ibidem, p. 161.
} 
congelado, esta figura de sí mismo que se le presenta bajo la forma de una exterioridad testaruda? ${ }^{29}$.

La Modernidad ha estado atravesada por la preocupación por identificar en el hombre un sustrato constitutivo en el que se jugaría la tensión entre la conciencia y la opacidad de su ser. En la configuración de la episteme moderna han confluido, así, la emergencia de la figura del hombre como productor de vida, de bienes y de significados, y la sombra de algo elusivo, que siempre se le escapa, de un "impensado" que le es tan propio como su conciencia:

El hombre y lo impensado son, en el nivel arqueológico, contemporáneos. El hombre no se pudo dibujar a sí mismo como una configuración en la episteme, sin que el pensamiento descubriera, al mismo tiempo, a la vez en sí y fuera de sí, en sus márgenes, pero también entrecruzados con su propia trama, una parte de noche, un espesor aparentemente inerte en el que está comprometido, un impensado contenido en él de un cabo a otro, pero en el cual se encuentra también preso ${ }^{30}$.

La tarea de las ciencias humanas ha consistido, por tanto, en hacer visible para el hombre las condiciones sobre las que se recorta ese horizonte de lo impensado, a través de un "develamiento de lo consciente" 31 , restituyendo así a los sujetos el pleno dominio de su propia individualidad creadora. La de Foucault, en cambio, ha sido, en buena medida, mostrar cómo allí donde parece irrumpir la marca de una conciencia fundadora es necesario desbrozar la compleja trama del "juego azaroso del discurso" 32 .

En El orden del discurso -la conferencia inaugural ofrecida en el Collège de France en 1970, al hacerse cargo de la cátedra de Historia de los sistemas de pensamiento- Foucault hace un gran esfuerzo para situar en un lugar adecuado el problema del vínculo entre el discurso, la verdad y el sujeto. No es en clave de ideología como se aborda el análisis, puesto que no se trata de un sujeto cuya visión de las cosas se halla obscurecida por el discurso del poder, ni de una manipulación engañosa de una verdad que se conoce pero se oculta. Tampoco se trata de una razón que va depurando el conocimiento separando la verdad del error. Mediante una referencia a uno de sus maestros, Georges Canguilhem, Foucault dice que para que una proposición sea verdadera o falsa -se trate tanto de una proposición científica, como filosófica o política- debe estar "en la verdad"33. En esta línea, su reflexión se ubica en el horizonte de la voluntad de verdad: “[...] cuál ha sido y cuál es constantemente, a través de nuestros discursos, esa voluntad de verdad que ha atravesado tantos siglos de nuestra historia" 34 .

Esta voluntad de verdad tiene que ver con los efectos de poder propios del juego enunciativo, con un régimen de enunciados que establece los criterios para definir lo verdadero y lo falso. De manera tal que para que una proposición pueda ser admitida en ese juego enunciativo, aun para ser considerada errada, tiene que ser formulada

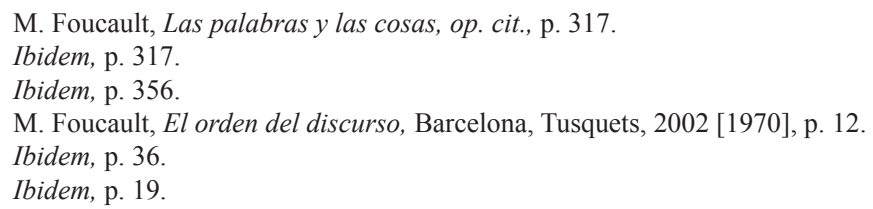


según la lógica de ese régimen. Hay sin duda puntos de apoyo institucionales que habilitan a la voluntad de verdad la posibilidad de ejercer sobre los discursos "una especie de presión y de poder de coacción" 35 . No obstante, el análisis foucaultiano se mantiene aquí en el ámbito del discurso, buscando dar cuenta de la constitución del sujeto en la trama histórica de los diversos regímenes de enunciados. Por esto los ejes de su reflexión pasan por el discurso al que puede imputarse el estatuto de "verdadero" y la voluntad de verdad:

El discurso verdadero, al que la necesidad de su forma exime del deseo y libera del poder, no puede reconocer la voluntad de verdad que lo atraviesa, y la voluntad de verdad que se nos ha impuesto desde hace mucho tiempo es tal que no puede dejar de enmascarar la verdad que quiere ${ }^{36}$.

En ese contrapunto entre discurso verdadero y voluntad de verdad se dibujan las líneas de fuerza que atraviesan la constitución histórica del sujeto moderno, ese sujeto que habita en la verdad y está atado a las obligaciones de verdad. Y aquí es interesante resaltar cómo el trabajo que proyecta Foucault para los años posteriores ya muestra la inquietud por explorar las condiciones de emergencia del sujeto de la gubernamentalidad liberal. Cuando establece los recorridos de su futura indagación dice que quiere dedicarse al sistema de exclusión que establece la oposición entre lo verdadero y lo falso a partir de un problema: "cómo se hizo, pero también cómo se repitió, prorrogó, desplazó esa elección de la verdad en cuyo interior estamos prendidos pero que renovamos sin cesar". Y para ello se va situar primero en la época de la sofística a fin de analizar el paso de un discurso ritual a uno que se afianza en la separación entre lo verdadero y lo falso; luego en la Inglaterra de la transición del siglo XVI al XVII donde se va configurando una ciencia de la mirada, de la observación, que articula una filosofía natural con la instauración de nuevas estructuras políticas; y finalmente en el siglo XIX, para abocarse a los "grandes actos fundadores de la ciencia moderna", contemporáneos a la formación de la sociedad industrial y a la definición de la ideología positivista que la acompaña ${ }^{37}$. El primer tramo de su trabajo va a estar reseñado en el curso de 1970/1, Lecciones sobre la voluntad de saber, mientras que el segundo coincidiría con los de 1972, Teoría e instituciones penales, y 1973, La sociedad punitiva, y el tercero, con los de 1974, El poder psiquiátrico, y 1975, Los anormales.

En esta secuencia van a ir apareciendo elementos que contribuyen a dar forma a los análisis del sujeto de la gubernamentalidad liberal. En la primera clase de Lecciones sobre la voluntad de saber, Foucault dice que podría haber dado el nombre de este curso a cualquiera de sus investigaciones previas, que, de un modo u otro, han abordado fragmentos para una morfología de la voluntad de saber. Y para el ciclo que se abre en el Collège de France su programa de investigación consistirá, según él, en reflexionar sobre esa voluntad de saber tal como aparece investida en indagaciones históricas determinadas, entre las que menciona específicamente la que se articula a los modos en que se estableció un saber de los procesos económicos entre los siglos XVI y XVIII ${ }^{38}$.

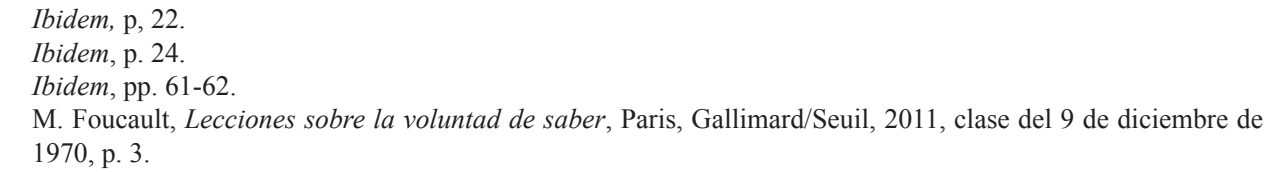


Si bien el curso de 1970/1 se dedica al problema de la verdad en la filosofía clásica, en los años siguientes Foucault va a enfocar su análisis en el tratamiento que recibe el problema del delito en el siglo XVIII, y va a encontrar que en ese contexto la estructura conceptual de la economía es la que provee la matriz de abordaje de la cuestión del control social: la preocupación política por el delito se vincula a la necesidad de regular los movimientos de la fuerza laboral y de racionalizar el equilibrio entre producción y consumo ${ }^{39}$. Foucault ubicaría aquí el despliegue de una voluntad de verdad que opera según la lógica de lo medible, lo cuantificable y lo útil, como había dejado entrever en la lección inaugural en el Collège de France ${ }^{40}$.

Ahora bien, ¿cómo se articulan verdad y gobierno? Si, como propone Foucault siguiendo a Canguilhem, para que pueda decirse de algo que es verdadero o falso hay que estar en la verdad, hay que habitar en la verdad, podríamos preguntarnos cuál es el modo de habitar en la verdad que está en el núcleo de la gubernamentalidad liberal.

En este sentido, el sujeto como conciencia soberana -uno de los constructos fundamentales de la Modernidad- es el efecto de una serie de técnicas de veridicción de sí mismo que han apuntado a volver a los individuos transparentes para sí y que configuran la trama del gobierno de los hombres en la historia occidental. En el resumen del curso dictado en 1980 en el Collège de France, Del gobierno de los vivos, Foucault sintetiza en una pregunta ese campo de análisis:

¿cómo es posible que en la cultura occidental cristiana el gobierno de los hombres exija de parte de los que son dirigidos, además de los actos de obediencia y de sumisión, 'actos de verdad' que tienen la particularidad de requerir que el sujeto no solo diga la verdad, sino que la diga acerca de sí mismo, de sus deseos, del estado de su alma $[\ldots]]^{31}$.

En sentido, la singularidad del gobierno en Occidente tiene que ver, según Foucault, con el lazo que lo ata a la verdad: la gubernamentalidad occidental se estructura en torno a la verdad. Por eso propone superar la oposición verdad / poder a partir de la noción "gobierno de la verdad" o "gobierno a través de la verdad". Mediante esta noción, según Foucault, es posible dar un contenido positivo a la relación saber / poder, que permite despegarse de lo que puede aparecer como una oposición binaria entre estos conceptos. Dice Foucault que lo que intenta hacer es una historia de la fuerza de lo verdadero, del poder de la verdad, para tomar la idea de la voluntad de saber desde otro ángulo ${ }^{42}$.

Pero, ¿cuál es la verdad a través de la cual se gobierna? La verdad de sí. Como inquiere Foucault: ¿cómo se formó ese tipo de gobierno que no sólo exige obedecer, sino también manifestar, enunciándolo, lo que somos ${ }^{43}$ ? Si bien es cierto, como

39 M. Foucault, La société punitive, Paris, Gallimard/Seuil, 2013, clase del 17 de enero de 1973, pp. 45-62.

40 " $[\ldots]$ en ciertos momentos de los siglos XVI y XVII (y en Inglaterra sobre todo) apareció una voluntad de saber que, anticipándose a sus contenidos actuales, dibujaba planes de objetos posibles, observables, medibles y clasificables [...]; una voluntad de saber que prescribía (y de un modo más general que cualquier otro instrumento determinado) el nivel técnico del que los conocimientos debían investirse para ser verificables y útiles" (M. Foucault, El orden del discurso, op. cit., p. 21).

41 M. Foucault, Del gobierno de los vivos, Buenos Aires, FCE, 2014, Resumen del curso, p. 359.

42 M. Foucault, Del gobierno de los vivos, op. cit., clase del 6 de febrero de 1980, p. 124.

$43 \quad$ Ibidem, p. 359. 
señala Edgardo Castro, que hacia fines de los ' 70 "la lectura gubernamental de la herencia grecolatina y cristiana" va tomando una fuerza creciente en el itinerario foucaultiano ${ }^{44}$, este salto de la racionalidad gubernamental del liberalismo clásico de los siglos XVIII y XIX y del neoliberalismo, de la segunda mitad del XX, al mundo antiguo y a los primeros siglos del cristianismo, operado en los cursos dictados a partir de 1980, no implica necesariamente un cambio de rumbo, en la medida en que hacer una historia de la gubernamentalidad liberal es al mismo tiempo hacer una historia de la subjetividad. Y el análisis de ese sujeto de la gubernamentalidad liberal -un sujeto transparente a sí mismo, que reconoce su propio interés y se adecúa a los estímulos del entorno- está inscripto en una pregunta genealógica que obliga a Foucault a mirar hacia atrás, hacia el punto en que se hacen visibles los vínculos que se tejen entre las relaciones de poder y los mecanismos productores de subjetividad:

Se trata de saber qué experiencia nos podemos hacer de nosotros mismos, qué campo de subjetividad puede abrirse la sujeto para sí mismo, desde el momento en que existen de hecho, históricamente, ante él, en relación a él, una cierta verdad, un discurso de verdad y una cierta obligación de ligarse a ese discurso de verdad -ya sea para aceptarlo como verdadero o para producir él mismo como verdadero ${ }^{45}$.

En relación a los vínculos entre el sujeto y la verdad, la confesión cristiana constituye una tecnología clave en la historia de la subjetividad moderna. Ese sujeto moderno al que Foucault alude a través de la figura del pliegue, y caracteriza como "forma psicológica de contemplación del yo" 46 se forja en buena medida sobre la matriz de la tecnología de la confesión como veridicción de sí mismo. La confesión está en el núcleo de ese proceso por el cual el hombre en Occidente se vio ligado a la obligación de manifestar la verdad de lo que él mismo es, en el devenir histórico de esa fuerza de lo verdadero de la que habla Foucault.

En este sentido, el cristianismo marca un punto de inflexión en la historia de la subjetividad occidental, porque es una religión que ata al individuo a obligaciones de verdad y mediante obligaciones de verdad. Estas obligaciones de verdad implican creer en una verdad revelada y explorar la verdad del sí mismo, y Foucault señala que entre ambas hay una relación de copertenencia, en tanto que la primera define el umbral de verdad que el sujeto debe buscar en su interior. Los efectos históricos del cristianismo como articulador de la idea de "Occidente" están ligados, como señala Paul Veyne, a esta "ética de la interioridad" que parece tener una potencia universal, puesto que puede dirigirse a cualquier hombre, y no sólo a un grupo de creencias reducido ${ }^{47}$.

Ahora bien, ¿cómo logra esta moral "de la gente sencilla”, como la define Veyne, modelar la subjetividad occidental? A través de la confesión, que Foucault ubica en la historia más general de las tecnologías del sujeto, caracterizadas como técnicas

44 E. Castro, “Gobierno y veridicción”, en M. Foucault, La inquietud por la verdad, Buenos Aires, S. XXI, 2013 , p. 21.

45 M. Foucault, Subjectivité et vérité, Paris, Gallimard/Seuil, 2014, clase del 14 de enero de 1981, p. 28 (traducción nuestra).

46 M. Foucault, El yo minimalista, Buenos Aires, op. cit., p. 79.

47 P. Veyne, Foucault. Pensamiento y vida, Barcelona, Paidós, 2014, p. 70. 
mediante las cuales los individuos, por sí mismos o con la ayuda o bajo la dirección de otros, van a transformarse y modificar su relación consigo mismo ${ }^{48}$.

Las tecnologías del sujeto de matriz cristiana exhiben dos rasgos distintivos: la obediencia como un valor formal en sí mismo y la "hermenéutica del pensamiento". En relación a la obediencia Foucault dice que aquí radica una de las características diferenciales con las tecnologías del mundo antiguo, que apuntaban al dominio de sí. En el cristianismo, en particular en las reglas del monacato, lo que importa es el hecho de obedecer como una forma de abandono de los propios impulsos y de entrega al que conduce. La humildad, la paciencia y la sumisión como valores inculcados por esas reglas implican, dice Foucault, la renuncia a uno mismo ${ }^{49}$.

En cuanto a la hermenéutica del pensamiento, también aparece una diferencia importante con respecto a las tecnologías de la Antigüedad, puesto que en éstas se exploraban las acciones, los comportamientos, los deseos, mientras que, según Foucault, la gran preocupación de la tecnología cristiana de la confesión es el modo en que se despliega el acto de pensar, y en particular el discurrir del pensamiento. El problema no es si el pensamiento se engaña con respecto a las cosas, sino si se engaña con respecto a sí mismo. El examen de conciencia cristiano se refiere al pensamiento ${ }^{50}$.

Aquí también hay otra cuestión central para la historia de la subjetividad occidental, que tiene que ver con la forma en que se analiza el pensamiento para ver si se engaña, y esa forma es hablar, y más aún, hablar delante de otro. Se forja así, diría Foucault, un principio de veridicción de sí mediante la hermenéutica del pensamiento: sabemos lo que somos cuando podemos interpretar el discurrir de nuestro pensamiento frente a otro - un otro real, como el sacerdote, o virtual, que podría ser Dios, o el superyó-. Este ejercicio de autoexaminarse y poner en palabras lo que el individuo ve dentro de sí, esta verbalización continua del yo, da cuenta de un elemento central "en la historia de la cultura y la subjetividad occidentales: el lenguaje" 51.

Esta hermenéutica del pensamiento que se configura a partir de la verbalización del yo es la que apunta a volver transparente la estructura psíquica del sujeto cognoscente. Foucault identifica con el momento cartesiano el punto de inflexión en la historia de la subjetividad occidental, en la medida en que en la figura de Descartes se condensa una imagen propia de la filosofía moderna que supone que el sujeto tiene los atributos necesarios para acceder a la verdad, a diferencia de la filosofía clásica que propone para esto un trabajo sobre sí mismo. Sin embargo es la autocontemplación del yo lo que provee el índice de la disponibilidad de estos atributos: es el pensamiento, y su propia mecánica de reflexión, lo que da cuenta de la posibilidad de conocer. Y en este juego se define un campo de oposición entre razón y sin-razón -sin-razón que un momento histórico determinado es identificada con la locura- ${ }^{-}$Tal como ya lo había planteado en la Historia de la locura, el cogito cartesiano excluye la locura en el ejercicio del pensamiento: yo, que pienso, no puedo estar loco. La locura justamente es condición de imposibilidad del pensamiento. Y el pensamiento excluye la locura ${ }^{52}$.

Este sujeto cognoscente es al mismo tiempo el sujeto gobernable de la Modernidad, en especial si pensamos en la racionalidad gubernamental del liberalismo,

48 M. Foucault, Obrar mal, decir la verdad, Buenos Aires, Siglo XXI, 2014, p. 33.

49 Ibidem, 155.

Ibidem, pp. 161-162.

Ibidem, p. 129.

52 M. Foucault, Historia de la locura en la época clásica, op. cit., Tomo I, pp. 78-79. 
que articula la verdad del mercado con la libertad como tecnología para recortar el campo de las acciones posibles para hombres y mujeres. Este modo de gobernar requiere un tipo de sujeto capaz de reconocer lo verdadero en su alma o su conciencia y de reconocer lo verdadero de la realidad, para responder en consecuencia. El homo oeconomicus que Foucault sitúa en el núcleo de la estrategia gubernamental del liberalismo es el hombre que acepta la realidad: la realidad de su propio interés cuya consecución persigue, la realidad de su entorno, ante la cual responde de manera no aleatoria sino racional -esto es, según una lógica medios/fines que presupone adecuada a sus objetivos-, la realidad de su propia biografía que dota al yo de profundidad histórica ${ }^{53}$.

De esta manera, el análisis de la gubernamentalidad liberal reconduce a las indagaciones sobre la locura a través del problema de la realidad. Si, como decíamos antes, las tecnologías propias de la razón gubernamental del liberalismo son las de seguridad, es decir las que toman a la realidad como punto de apoyo, el problema con la locura es, en la perspectiva del saber psiquiátrico que acompaña la consolidación del orden liberal-burgués, que el loco no acepta la realidad: la realidad de su propia biografía, la realidad del poder del psiquiatra, la realidad de la enfermedad. "Dejar de estar loco es aceptar ser obediente, ganarse la vida, reconocerse en la identidad biográfica que han forjado para uno". Foucault caracteriza, incluso, a la terapéutica de la psiquiatría del siglo XIX, en particular la que se despliega en las instituciones de encierro, como un "intensificador de realidad" 54 .

Si la del loco es una voluntad insurrecta ${ }^{55}$, la del homo oeconomicus es una voluntad depurada, racionalizada, bajo la forma del interés ${ }^{56}$. Y esta voluntad depurada resulta de la capacidad del sujeto de conocerse a sí mismo y reconocer en la mecánica de su pensamiento y de su deseo aquello que quiere, aquello que busca, aquello que le conviene y lo satisface.

Aquí se plantea una pregunta: de qué manera la obligación que recae sobre el individuo de buscar en sí mismo la verdad de lo que es se vuelve un acto políticamente fértil, consustancial a la conformación de las instituciones políticas y jurídicas características de Occidente. En principio, porque el individuo que sabe lo que es y lo que quiere es un sujeto gobernable. Es un sujeto moral, si por esto entendemos, en un sentido lato, un sujeto que reconoce que debe conformar su conducta al juego de interacciones en el que lo sitúa la convivencia social. Y esto hace que sean las acciones de los demás las que contribuyan a fijar los límites, permitiéndole al arte de gobernar regularse según el principio de la economía -en los dos sentidos del término: como economía política, y como restricción, autolimitación, frugalidad del gobierno-. Si el gobierno puede ser frugal es porque hay un sujeto que se reconoce a sí mismo como buscador de interés y que a la vez encuentra los límites de sus acciones posibles en otros tantos sujetos que, como él, persiguen su propio su interés.

Si bien es cierto, como sugiere Christian Laval, que la reivindicación de la plena legitimidad de obedecer ante todo al propio interés puede ser considerada, en relación a otras morales sociales que promueven la búsqueda del bien común, como una

\footnotetext{
M. Foucault, Nacimiento de la biopolítica, op. cit., clase del 28 de marzo de 1979, p. 308.

M. Foucault, El poder psiquiátrico, op. cit., clase del 19 de diciembre de 1973, p. 196.

Ibidem, p. 199.

56 M. Foucault, Nacimiento de la biopolítica, op. cit., clase del 28 de marzo, p. 314. Este planteo de Foucault puede enriquecerse con el maravilloso libro de Albert Hirschmann, Las pasiones y los intereses, México, FCE, 1978, passim.
} 
extraña transposición de valores, aun así contribuye a forjar un tipo de sujetos morales que definen un umbral a partir del cual es posible agenciar el gobierno del mundo social $^{57}$. El homo oeconomicus abona la racionalidad gubernamental del liberalismo, en la cual la obediencia a la ley está garantizada por la lógica del interés que mueve a los individuos egoístas a transferir a un tercero arbitral -el Estado- la resolución de los litigios en los que puedan estar involucrados, aportando así, indirectamente, a la convivencia social. En este marco, según Foucault, el liberalismo no se recostó en la ley por un "juridicismo que le fuera natural" sino porque

la ley define formas de intervenciones generales excluyentes de medidas particulares, individuales y excepcionales, y porque la participación de los gobernados en la elaboración de la ley, en un sistema parlamentario, constituye el modo más eficaz de economía gubernamental ${ }^{58}$.

\section{La subjetividad y el ethos crítico moderno}

Del gobierno de las poblaciones según la lógica biopolítica propia de la gubernamentalidad liberal, Foucault se desplaza, hacia fines de la década de 1970, al problema del gobierno de sí mismo a través del análisis de las prácticas de sí del estoicismo, el epicureísmo y el cristianismo. Este desplazamiento no deja de sorprender si leemos su relato acerca de cómo está organizando su itinerario de indagación. En el resumen con el que cierra Nacimiento de la biopolítica señala que finalmente se dedicó a analizar lo que en principio había sido pensado como una introducción al problema de la biopolítica, esto es, el liberalismo como marco general de la biopolítica. Por lo tanto este tema que quedó pendiente, afirma, concentrará su atención el año siguiente. De ahí el título presentado en la primavera de 1979 para el próximo curso: "Del gobierno de los vivos". Sin embargo, como vimos, aquí pone el foco en el vínculo entre gobierno y verdad de sí a partir del análisis de la confesión y la penitencia.

La relación entre biopolítica y liberalismo va perdiendo centralidad al menos en sus indagaciones más sistemáticas y el giro hacia la Antigüedad clásica y tardía y el cristianismo ocupan su atención en los últimos años. No obstante, la Modernidad sigue presente en ese giro a través de la inquietud por el ethos crítico que la caracteri$\mathrm{za}, \mathrm{y}$ que se manifiesta en la problematización de lo que son, lo que hacen y el mundo en que viven que despliegan sin cesar las mujeres y los hombres ${ }^{59}$.

Por eso no sorprende que introduzca el curso de 1983, El gobierno de sí y de los otros -dedicado a la filosofía y a la tragedia griegas del período clásico- con una clase en la que analiza el texto de Immanuel Kant "Respuesta a la pregunta ¿Qué es la ilustración?". Este texto, inscripto según Foucault en la tradición kantiana de la ontología del presente, de la actualidad, de nosotros mismos ${ }^{60}$, define la Ilustración por una cierta actitud, un ethos filosófico que se caracteriza por la crítica permanente de nuestro ser histórico y por el compromiso con esa tarea de reflexión en torno a lo

\footnotetext{
C. Laval, L'homme économique. Essais sur les racines du néolibéralisme, Paris, Gallimard, 2007, p. 11.

M. Foucault, Nacimiento de la biopolítica, op. cit., "Resumen del curso", p. 363.

M. Foucault, "Usages des plaisirs et techniques de soi”, en Dits et écrits, Paris, Gallimard, 1994, T. IV, p. 544.

60 Foucault filia en Kant dos tradiciones: una analítica de la verdad que se referencia en la Crítica de la razón pura, y una ontología del presente, en la cual el propio Foucault inscribe su indagación. Cf. M. Foucault, Le gouvernement de soi et des autres, op. cit., clase del 5 de enero de 1983, p. 22.
} 
que somos en nuestra propia actualidad ${ }^{61}$. Y es este ethos crítico característico de la Modernidad lo que define para la filosofía la tarea de decir el sentido del presente ${ }^{62}$. La respuesta kantiana que identifica la Ilustración con la salida de la minoría de edad -entendida como la aceptación acrítica de lo que se nos dice- implica, para Foucault, situar en el núcleo del desafío de la Modernidad una nueva distribución de la relación entre gobierno de sí y gobierno de los otros: pensar por uno mismo es una forma de disputar un espacio propio en el terreno del gobierno ${ }^{63}$.

Por oposición a la minoría de edad que implica falta de autonomía, el ethos crítico moderno nos empuja a pensar por nosotros mismos en relación a las condiciones de constitución histórica de nuestro ser. Ya en el estudio que precede al texto kantiano Antropología en sentido pragmático - tesis complementaria de Foucault presentada junto con la tesis principal sobre la locura, y resultante de un trabajo realizado entre 1959 y 1960 según los editores del escrito-, ${ }^{64}$ aparece la inquietud por definir los rasgos de un "homo críticus", cuya estructura cabría interrogar a fin de analizar si difiere "en lo esencial del hombre que lo ha precedido". Habría que indagar el modo en que una nueva crítica de la verdad pudo haber constituido el umbral en el que se hace posible una nueva forma de articulación del sujeto con esa verdad:

Es decir, la Crítica, en su carácter propio de 'propedéutica' de la filosofía, añadiría un papel constitutivo en el nacimiento y el devenir de las formas concretas de la existencia humana. Habría cierta verdad crítica del hombre, hija de la crítica de las condiciones de la verdad [destacado en el original $]^{65}$.

No obstante, la filosofía contemporánea propone otra lectura de Kant, buscando en la crítica kantiana a la ilusión trascendental un suelo antropológico que opere como el fundamento y la posibilidad de las ciencias humanas. Foucault, en cambio, afirma que en la propuesta kantiana, la crítica no permite "hablar otro lenguaje que el del límite y la negatividad"66, y sitúa su indagación en ese límite, como puede verse en Las palabras y las cosas, donde analiza con detenimiento la confusión que exhibe el pensamiento moderno en relación a lo empírico y lo trascendental, "cuya

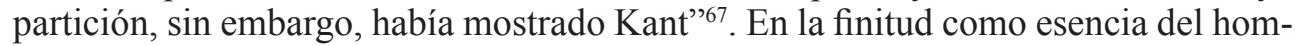
bre, éste se va a configurar como un 'extraño duplicado empírico-trascendental' cuyo conocimiento da cuenta "de todo aquello que hace posible el conocimiento" 68 . La filosofía moderna queda, por tanto, presa de un "sueño antropológico", según el cual

Todo conocimiento empírico, siempre y cuando concierna al hombre, vale como posible campo filosófico, en el que debe descubrirse el fundamento del conoci-

62

63

64

\footnotetext{
Ibidem, p. 32. Aires, S.XXI, 2009, p. 33.

65 Ibidem, p. 41.

66 Ibidem, p. 128

67 M. Foucault, Las palabras y las cosas, op. cit., p. 331.
}

M. Foucault, “Qu'est-ce que les Lumières?”, en Dits et écrits, op. cit., T. IV, p. 562-578.

M. Foucault, Les gouvernement de soi et des autres, op. cit., clase del 5 de enero de 1983, p. 15.

En la presentación que hacen Daniel Defert, François Ewald y Frédéric Gros, se hace mención a esos años como el período del trabajo de Foucault sobre el texto de Kant, dado que coinciden con su desempeño como director del Instituto Francés de Hamburgo, muy cerca de Rostock, donde se conservaban los papeles del filósofo alemán. Cf. M. Foucault, Una lectura de Kant. Introducción a la Antropología en sentido pragmático, Buenos

$68 \quad$ Ibidem, p. 310. 
miento, la definición de sus límites y, por último, la verdad de toda verdad. La configuración antropológica de la filosofía moderna consiste en desdoblar el dogmatismo, repartirlo en dos niveles diferentes que se apoyan uno en otro y se limitan uno a otro: el análisis precrítico de lo que el hombre es en su esencia se convierte en la analítica de todo aquello que puede darse en general a la experiencia del hombre ${ }^{69}$.

El desafío kantiano que Foucault intenta retomar, en cambio, es el que se define en la Antropología en sentido pragmático: el compromiso con una cuestión de método que explora "un camino que ya está previsto que jamás encontrará su término en una verdad de naturaleza" . En esta línea se inscriben sus análisis de las formas históricas de subjetivación, que intentan poner en cuestión el carácter a priori del sujeto: como propone en la Historia de la sexualidad..., se trata de reconstruir los modos a través de los cuales los individuos intensifican la relación consigo mismos erigiéndose en sujetos de sus actos ${ }^{71}$.

Esta indagación, que lo lleva a la filosofía griega clásica, al helenismo y al cristianismo, mantiene un estrecho vínculo con el presente y se despliega según la lógica de ese ethos crítico de la Modernidad, en tanto intenta señalar cómo hemos sido constituidos y qué de esas formas de constitución ya no es necesario para actuar como sujetos autónomos ${ }^{72}$. El trabajo de Foucault apunta a mostrar, en definitiva,

que la gente acepta como verdad, como evidencia, algunos temas que han sido construidos durante cierto momento de la historia, y que esa pretendida evidencia puede ser criticada y destruida ${ }^{73}$.

En la lógica de la parrhesía que él mismo analiza, Foucault asume el gesto valeroso del decir veraz, el hablar franco, en relación a la constitución histórica de nosotros mismos. Este gesto determina una situación abierta que vuelve posible una cantidad de alternativas desconocidas; no produce un efecto codificado, sino que se abre al riesgo de lo indeterminado ${ }^{74}$. Y es ese espacio de lo indeterminado donde la propuesta foucaultiana nos permite pensar en modos diversos de configuración de la verdad en relación a los demás y a nosotros mismos que habiliten otras experiencias subjetivas posibles.

\section{A modo de cierre}

Para reconstruir la genealogía del sujeto moderno, la producción de Michel Foucault ofrece aportes clave que permiten comprender tanto la configuración subjetiva que hace de la conciencia soberana de los individuos el motor de todo pensamiento y acción, como las estrategias gubernamentales que se forjan en virtud de ese supuesto. En este sentido, el análisis de la gubernamentalidad liberal propuesto por Foucault en

\footnotetext{
Ibidem, p. 332.

M. Foucault, Una lectura de Kant..., op. cit., p. 68.

M. Foucault, Historia de la sexualidad. 3-La inquietud de sí, Madrid, Siglo XXI, 1987, p. 40.

M. Foucault, "Qu'est-ce que les Lumières?”, en Dit et écrits, op. cit., p. 572.

M. Foucault, "Verdad, individuo y poder", en Tecnologías del yo, Paidós, Buenos Aires, p. 143.

M. Foucault, Le gouvernement de soi et des autres, op. cit., clase del 12 de enero de 1983, p. 56.
} 
Seguridad, territorio, población y en Nacimiento de la biopolítica, que gira en torno a la libertad como tecnología de gobierno, conecta claramente la figura del hombre como sujeto de conciencia - problematizada en los trabajos de la década de 1960con la del homo oeconomicus, el individuo racional, calculador y adquisitivo, cuya acción se orienta a partir de la articulación de su propio interés con los indicadores que le ofrece la realidad.

El homo oeconomicus es la forma en que se activa, en la estrategia gubernamental del liberalismo, el sujeto como pliegue, como autocontemplación psicológica del yo: sólo el individuo capaz de reconocer en el interior de su ser la verdad de su propio interés, adecuándola a la verdad que reconoce en su entorno, puede actuar persiguiendo sus fines y ser gobernado con la libertad de un dejar hacer en el que las intervenciones políticas se minimizan en beneficio de lo que se supone que serán los límites espontáneamente fijados a las conductas por el mecanismo concurrencial del mercado.

Sin embargo, esa matriz subjetiva que le permite al liberalismo gobernar con la libertad, según un límite establecido por la verdad del mercado, es el producto de una serie de tecnologías que ligan a los individuos a una verdad de sí, que los inducen a buscar sin cesar la verdad de lo que son, de lo que hacen, de lo que desean. Estas tecnologías hunden sus raíces en la Antigüedad, pero encuentran un punto de inflexión en el cristianismo, puesto que la confesión y la penitencia cristianas empujan a los hombres y mujeres a indagar en la verdad de su pensamiento a través de una verbalización continua de sí mismos.

Es por esto que los trabajos de Foucault dedicados a la Antigüedad clásica y tardía y al cristianismo siguen aportando al análisis de la subjetividad moderna y a las formas en que ésta habilita una superficie de intervención del gobierno, entendido en sentido amplio como control de conductas. Si el liberalismo puede gobernar con la libertad -a la que el neoliberalismo sumará como elemento distintivo la competencia- es porque presupone sujetos que, a través de diversas técnicas orientadas a la exploración de la verdad de sí, son capaces de dar cuenta de sus intereses y sus deseos y de articularlos con los estímulos de la realidad. En definitiva, la gubernamentalidad liberal está ligada a esta historia de la potencia de la verdad que Foucault intenta rastrear a lo largo de los siglos en Occidente.

No obstante, el análisis de ese poder de lo verdadero que nos fuerza a decir lo que somos y nos ata a una identidad se vuelve, en el itinerario foucaultiano, el punto de apoyo de una estrategia orientada a mostrarnos que podemos ser, dice Foucault, más libres de lo que creemos: puesto que esto que somos es el producto de una serie de tecnologías históricamente gestadas, es posible ser algo distinto. En la línea de la ontología del presente de matriz kantiana, Foucault asume el gesto político de hacer visible el carácter arbitrario de aquello que se ha naturalizado, y recupera el ethos crítico de la Modernidad para explorar los modos de configuración de una estética de la existencia, una biopoética que nos permita "fabricar" nuestra propia vida en el marco de una conducta estético-moral ${ }^{75}$.

75 M. Foucault, Subjectivité et vérité, op. cit., clase del 14 de enero de 1981, p. 37. 